\title{
GRANDEZAS E MEDIDAS: DA ORIGEM HISTÓRICA À CONTEXTUALIZAÇÃO CURRICULAR
}

\section{GREATNESS AND MEASUREMENTS: FROM HISTORICAL ORIGIN TO CURRICULAR CONTEXTUALIZATION}

\author{
João Pedro Mardegan Ribeiro ${ }^{1}$ \\ Universidade de São Paulo (USP)
}

\begin{abstract}
Resumo
O presente artigo tem como finalidade apresentar por meio de uma análise crítica a importância dos aspectos das grandezas e suas unidades de medida nas práticas de ensino e aprendizado de matemática, com base em documentos curriculares oficiais brasileiros e, também, em teóricos da área de educação matemática. O trabalho é dividido entre uma análise crítica dos documentos curriculares oficiais brasileiros que expõem a importância do aprendizado efetivo das grandezas e suas unidades de medida na educação básica, e também um breve relato histórico acerca da origem das grandezas e a importância que esta teve para o crescimento e evolução da sociedade, percorrendo deste as primeiras manifestações humanas, até os dias de hoje. Este trabalho foi realizado a partir de uma análise bibliográfica na literatura, em obras disponíveis em museus, bibliotecas e em revistas científicas disponíveis virtualmente, e foi desenvolvido por três agentes, uma professora da Universidade de São Paulo, filiada ao grupo de Educação Matemática do Instituto de Ciências Matemáticas e de Computação (ICMC/USP), um aluno de Iniciação Científica, e uma professora da rede pública de ensino, responsável pela elaboração das ilustrações. Em linhas gerais, uma abordagem histórica acerca dos aspectos que norteiam todo um padrão de medidas, pode contribuir na construção do saber para com os alunos, uma vez que estes vão perceber que as grandezas e suas respectivas unidades de medida são de suma importância para a construção da sociedade como um todo, e estão interligadas a todas as atividades humanas.
\end{abstract}

Palavras-chave: Grandezas e suas unidades de medida; Educação Matemática; História da Matemática.

\begin{abstract}
The purpose of this article is to present, through a critical analysis, the importance of aspects of quantities and their units of measurement in mathematics teaching and learning practices, based on official Brazilian curriculum documents and also on education mathematics theorist. The work is divided between a critical analysis of the official Brazilian curriculum documents and also of elementary school that exposes the importance of effective learning of quantities and their units of measurement in basic education, and also a brief historical account about the origin of quantities and the importance that it had for the growth and evolution of society, going from this the first

\footnotetext{
${ }^{1}$ E-mail: joao.mardegan.ribeiro@usp.br.
} 
human manifestations, until today. This work was carried out from a literature review, works available in museums, libraries and virtually available scientific journals, and was developed by three agents, a professor from the University of São Paulo, affiliated to the Mathematical Education group of the Institute of Mathematical and Computer Sciences (ICMC / USP), a student of Scientific Initiation, and a teacher of the public school, responsible for the elaboration of the illustrations. In general terms, a historical approach to the aspects that guide a whole standard of measurement can contribute to the construction of knowledge for the students, since they will realize that the magnitudes and their respective units of measurement are of paramount importance for the students. construction of society as a whole.

Keywords: quantities and their units of measure; Mathematics education; History of Mathematics.

\section{Introdução}

Uma das tarefas mais difíceis para o professor hoje, da área de matemática, é, de fato, despertar o interesse dos alunos por conteúdos ligados à matemática, uma vez que os alunos estão cada vez mais desinteressados em aprender, e criando aversão aos conteúdos inerentes a esta área. De certo, a matemática está presente em todas as práticas das relações humanas, por isso é uma das linguagens universal, já que interliga todos os processos da práxis humana. Devido a isto, é importante que o professor consiga despertar nos alunos o interesse em participar da interação com o conteúdo matemático, para que assim ele possa contribuir ativamente na construção da sociedade.

O ensino de matemática na educação básica é substancial para o aluno compreender o mundo a sua volta, e interagir com a sociedade de forma crítica e pontual, participando ativamente da sua realidade. De fato, as aplicações dos pressupostos matemáticos constroem um mundo civilizado e organizado com base nas perspectivas correlatas a ação e reação da globalização. Ou seja, qualquer atividade, a qualquer hora do dia, o conhecimento matemático, mesmo que básico, está presente, e se faz necessário. Assim, de certo, um dos grandes desafios da matemática é desenvolver competências nos alunos necessárias para o exercício pleno da cidadania. Para que um aluno consiga aprender é necessário que os professores potencializem nestes o domínio pela leitura, a escrita e o conhecimento matemático, de maneira que eles consigam compreender o mundo à sua volta, criando valores que fundamentam a sociedade. 
A valer, os conteúdos curriculares da matemática no ensino fundamental tratam de ações que realizamos no dia a dia, todavia, muitas vezes em sala de aula a forma como o professor ministra este o conteúdo, acaba se tornando algo muito abstrato, difícil e confuso. Devido a isso os alunos criam aversão a estes conteúdos. Assim, abordar aspectos da própria história em aulas de matemática pode potencializar o processo de aquisição do conhecimento, como também ficar mais atraente aos alunos, uma vez que eles vão compreender a importância de estudar tais fatos.

Com esta perspectiva em mente, entra os aspectos da História da Matemática correlacionados diretamente aos aspectos da história das ciências e da sociedade como um todo, uma vez que a matemática foi, e ainda é, um dos fenômenos que estão diretamente ligado a evolução gradual da sociedade, e a sustenta para cada vez mais haver desenvolvimento científico e tecnológico. Deste modo, as grandezas e suas unidades de medida vieram, dentro da história da matemática, como ferramenta que sustentou e se tornou um pilar para que padrões mais concretos no comércio, na produção de bens de consumo e no desenvolvimento científico ficassem mais eficientes.

O homem começou a fazer as primeiras medições para uso na agricultura, e estas se tornaram fundamentais, especialmente com o desenvolvimento do comércio, auxiliando o fortalecimento das relações sociais desenvolvidas e na criação de padrões que tivesse significado nas trocas de bens. Com o desenvolvimento também da ciência e tecnologia, as grandezas e suas unidades de medida foram substanciais para uma análise mais precisa e coerente na quantificação de dados. Neste sentindo, os conteúdos inerentes aos aspectos das Grandezas e Medidas trazem grandes contribuições, uma vez que possuem estreitas relações com as diversas áreas das atividades humanas, sendo, de fato, aplicadas em distintas situações do cotidiano. Analisando as Diretrizes Curriculares Nacionais de Matemática (BRASIL, 1998), o tema Grandezas e Medidas desempenha papel de suma importância, uma vez que permeia todas as séries dos ensinos fundamental e médio.

Os padrões de medida, nos dias de hoje, são cruciais na eficiência da realização de alguns fenômenos e de certas medidas, como medidas muito pequenas para estudos de partículas e interações atômicas e subatômicas, distâncias muito elevadas em astronomia, assim como, plantas, estruturas e projetos em engenharia e arquitetura. De certo, com o surgimento de novas descobertas e necessidades temporais, a importância 
das medidas vem sendo reafirmada cada vez mais e, também, se adaptando a certas condições.

Considerando que no Brasil há uma carência de trabalhos que discorrem sobre a abordagem histórica no ensino das grandezas e suas unidades de medida e sua importância, como também há falta de materiais didáticos coerentes com a linguagem da história da ciência, e tendo em vista as informações supracitadas, este artigo tem como finalidade expor o resultado de uma pesquisa acerca dos aspectos históricos das grandezas e suas unidades de medida, e a importância da abordagem cultural desta dentro das atividades de matemática na educação básica. As características do campo de pesquisa desenvolvido, os documentos de orientações curriculares, livros didáticos e paradidáticos das escolas públicas, tal como os teóricos desse campo, como Fiorentini e Lorenzato (2006), definem esta pesquisa como bibliográfica.

\section{Metodologia da pesquisa e do desenvolvimento do trabalho}

Tendo em vista as informações supracitadas acerca da importância das relações entre o ensino e o aprendizado dos conceitos das grandezas e suas unidades de medida, e considerando também os aspectos históricos envolvidos, os teóricos da área de ensino de matemática e também os documentos oficiais curriculares brasileiros, o objetivo deste trabalho foi fazer uma busca na literatura acerca da origem das grandezas e suas unidades de medida, assim como estudar a importância que estas apresentam referente às práticas de ensinagem de matemática e elaborar um texto que possa ser utilizado por professores durante as práticas de ensino dos conteúdos inerentes à área em questão.

Durante o XII Encontro Ibero-Americano de Educação realizado na Espanha (2017), os agentes envolvidos neste trabalho aprenderam mais sobre a importância de envolver processos históricos nas práticas de ensino nas disciplinas das ciências exatas e naturais como forma de contextualização e inserção do conteúdo na realidade dos alunos, assim, voltando ao Brasil, houve a criação de um projeto de pesquisa em forma de Iniciação científica financiado pela pró-reitoria de graduação da Universidade de São Paulo, voltado ao estudo da importância e inserção destes processos históricos envolvidos no ensino das Grandezas e medidas integrado as aulas de matemática. 
Em consonância com o objetivo geral do trabalho, foi adotado a seguinte sequência de execução das atividades:

Etapa 1: Levantamento e análise crítica dos documentos curriculares oficiais brasileiros do ensino fundamental e do ensino médio, tais como: Parâmetros Curriculares Nacionais (BRASIL, 1998), Currículo do Estado de São Paulo da área de matemática, a Base Nacional Comum Curricular (BRASIL, 2018) e as Diretrizes Curriculares Nacionais da Educação Básica (BRASIL, 2013);

Etapa 2: Revisão de Literatura analisando obras de teóricos que discorrem sobre a importância do ensino das grandezas e medidas e, também, das abordagens históricas nas práticas de ensino;

Etapa 3: Busca em periódicos disponíveis, como também em obras disponíveis em museus, bibliotecas, revistas e livros didáticos e paradidáticos sobre os aspectos históricos da origem e evolução dos conceitos relacionados às grandezas e medidas;

Etapa 4: Elaboração de um texto apoio sobre a origem das Grandezas e suas unidades de medida para uso dos professores no início das abordagens sobre a temática.

\section{Fundamentação teórica: as Grandezas e suas unidades de medida segundo os documentos curriculares oficiais brasileiros e teóricos da área de Educação Matemática}

\subsection{Documentos oficiais brasileiros do Ensino Médio}

De maneira substancial, o desenvolvimento dos conceitos de grandezas e suas respectivas unidades de medida são indicados nos documentos curriculares oficiais brasileiros, tais como nos PCN (BRASIL, 1998), e Currículo do Estado de São Paulo (SÃO PAULO, 2012), das mais distintas áreas, e de certo, ao pesquisar sobre as perspectivas históricas dos conceitos de grandezas e suas unidades de medidas em disciplinas da Licenciatura em Matemática, há necessidade de referenciais sobre esse tema.

Uma boa visão histórica acerca da matemática, como das ciências em geral, mostra para o aluno que ela foi, e é construída por problemas gerados por uma ordem prática, e de necessidades temporais da sociedade. E essa visão humanística fornece uma contribuição significativa para o processo de ensino e aprendizado em matemática. 
Isto é citado nos Parâmetros Curriculares Nacionais (BRASIL, 1998), uma vez que este indica que é importante relacionar as etapas da história da matemática com a evolução da humanidade, já que ultrapassa a relação social e forma um panorama sobre o desenvolvimento e a evolução dos conceitos que serão aprendidos.

No currículo do Estado de São Paulo (São Paulo, 2012), é enfatizado que é contando histórias que os significados são construídos, já que ainda que seja possível ensinar os conteúdos conceituais tais como eles são apresentados aos alunos, é necessário considerar que eles se transformam, uma vez que eles têm uma história. E é a partir dos pressupostos históricos que adquirimos uma compreensão mais visível acerca dos significados dos conceitos mais fundamentais, e principalmente, a mudança conceitual torna-se facilitada.

Nos Parâmetros Curriculares Nacionais da Matemática (BRASIL, 1998), na área de Investigação e compreensão, é citado a importância da identificação dos fenômenos naturais ou das grandezas em dado domínio do conhecimento científico, como também a importância de estabelecer relações, identificar regularidades, invariantes e transformações, percebendo, em linhas gerais as relações e identidades entre diferentes formas de representação de um dado objeto, como as relações entre representações planas nos desenhos, mapas e telas de computador com os objetos que lhes deram origem.

No que diz respeito aos aspectos das medidas, quantificações, grandezas e escalas, nos PCN (BRASIL, 1998) é dito sobre a importância dos alunos saberem selecionar, tal como utilizar instrumentos de medição e de cálculo, representar dados e utilizar escalas, fazer estimativas, elaborar hipóteses e interpretar resultados, usando efetivamente os aspectos das grandezas e suas unidades de medida, uma vez que há necessidade dos alunos saberem estes princípios, para que assim façam o uso adequado de formas e instrumentos de medida para estabelecer comparações quantitativas e também fazer previsões acerca de certos fenômenos.

No que tange a área de Química e Física (BRASIL, 1998) é citado à importância do reconhecimento e também da utilização adequada, seja na forma oral quanto escrita, dos símbolos, códigos e nomenclaturas da Linguagem científica, usando para isso conhecimentos de identificação e reconhecimento das unidades de medida usadas para 
as diferentes grandezas, seja elas: massa, energia, tempo, volume, densidade, concentração de soluções, entre outros.

Ainda na área dessas Ciências Naturais, nos PCN (BRASIL, 1998) é citada a relevância dos estudos de medidas, quantificações, grandezas e escalas. Os alunos devem saber selecionar e utilizar instrumentos de medição e de cálculo, tal como saber representar dados e utilizar escalas e, também, fazer estimativas, elaborar hipóteses e interpretar resultados, isso para fazer previsões, elaborar hipóteses e estimativas que colaborem no exercício eficiente de certa atividade.

\subsection{Documentos curriculares oficiais brasileiros do Ensino Fundamental}

Nos Parâmetros Curriculares Nacionais do Ensino Fundamental da área de matemática (BRASIL, 1998), no que diz respeito às grandezas e medidas, é criado um bloco expandido que expõe toda a importância desta para o contexto social do aluno, e como este contribui de maneira substancial para a construção da sociedade. As grandezas e suas medidas caracterizam-se por sua forte relevância social, uma vez que apresenta um caráter prático e unitário que faz grande conexão com outras áreas do conhecimento. Referente à vida em sociedade, de fato, as grandezas e suas unidades de medida estão substancialmente presentes em quase todas as atividades humanas, deste modo, desempenha um papel primordial no currículo de matemática, uma vez que mostra aos alunos que este conteúdo está inserido diretamente no cotidiano.

Segundo os PCN (BRASIL, 1998), no que se refere às atividades desenvolvidas e exploradas nesta área, elas proporcionam aos alunos uma maior e melhor compreensão de conceitos relativos ao espaço e, também, às formas. E assim, de maneira geral e integrada, as grandezas trazem à tona contextos muito rico para o trabalho com os significados dos números, tal como das operações e também abre espaço para uma rica e eficaz abordagem histórica. Também é enfatizado a importância de proporcionar aos alunos experiências que permitam que estes ampliem sua compreensão sobre os processos de medição, percebendo que as medidas são úteis para descrever e comparar fenômenos.

Tem-se que estudar as diferentes grandezas e suas respectivas unidades de medida, devido ao seu caráter social e de solução de problemas históricos pode despertar o interesse dos alunos. O professor pode fazer uma abordagem gradual e 
integrada, ou seja, a exploração de medidas referente a comprimento, massa, capacidade, superfície, tempo, temperatura, iniciada em ciclos anteriores, é ampliada gradualmente para que o estudo de ângulos, volume, e algumas medidas atuais da área de informática como quilobytes, megabytes sejam facilitadas.

O professor, considerando os aspectos e trabalho com as medidas, pode, substancialmente, centrar e favorecer uma grande análise acerca de situações práticas que podem levar o aluno a aprimorar o seu saber baseado no real sentido das medidas.

Por meio de situações-problema, extraídas dos contextos práticos em que essas grandezas se encontram como na arquitetura, nas artes, nos esportes, na culinária, nas atividades comerciais e na leitura de mapas, plantas e croquis evidenciam-se para os alunos as aplicações práticas da Matemática e a necessidade de contar com unidades padronizadas e com sistemas comuns de medida e também a necessidade de encontrar estimativas plausíveis. A natureza aproximada das medidas constitui um aspecto numérico que merece atenção especial. Além de orientar os alunos para que desenvolvam estratégias de estimativa e aprendam a julgar o grau de exatidão necessário para uma situação particular, é importante ensiná-los a utilizar adequadamente instrumentos como balanças, relógios, escalímetro, transferidor, esquadro, trenas, cronômetros e a selecionar os instrumentos e as unidades de medida adequadas à exatidão desejada. Além de fornecer os contextos práticos para a realização da atividade matemática é importante pensar nas Grandezas e Medidas como um bloco que possibilita férteis articulações com os outros blocos de conteúdos, uma vez que seu estudo está fortemente conectado com o estudo da Geometria e com os diferentes tipos de números (BRASIL, 1998, p. 69)

Na BNCC (BRASIL, 2018, p. 267), no que tange as competências especificas de matemática para o Ensino Fundamental, a primeira competência citada refere-se à importância dos alunos compreenderem que a matemática deve ser reconhecida como um fruto das necessidades e preocupações de diferentes culturas, tal como em diferentes momentos históricos, que visa à solução de problemas de uma ordem global para todos os povos. Esta competência, de fato, pode ser atingida com base em abordagens históricas em sala de aula.

Nas Diretrizes Curriculares Nacionais do ensino fundamental (BRASIL, 2013), no que se refere à reinvenção do conhecimento e a apropriação da cultura pelos alunos, é citado que as relações específicas entre a leitura e a escrita, a História, as Ciências, e a Arte, proporcionam aos alunos o encontro com um mundo diferente, e de tal maneira, mais amplo e diversificado que o seu. Também é feita uma complementação de que quando o professor não restringe as práticas de ensino a somente a transmissão de conhecimentos acabados, e sim, apresenta o conhecimento como algo de construção gradual e não verdade acabada, os alunos percebem que a forma de expressar a 
realidade pode vir atrelada a outras interpretações, assim, a escola pode vir a oferecer um espaço para os educandos reinventarem o conhecimento, e assim, criarem e recriarem a cultura. Deste modo, no que tange aos professores de matemática, quando há abordagem rica em contextualizações, seja referente à natureza das ciências, como também por meio do ensino da história da matemática, os alunos percebem que podem fazer parte do processo de aperfeiçoamento da cultura e modificá-la para melhorar as relações da sociedade.

\subsection{Teóricos da área de Ensino de Matemática}

Nos trabalhos de Kula (1999), Crease (2013) e Silva (2010) há discussão acerca da importância da medição, inclusive como fator essencial para o desenvolvimento da humanidade, interligado também aos aspectos da comunicação, considerando que pesos, escalas e medidas estão de maneira substancial integrada à nossa vida. Desenvolvem também a história da invenção e a importância da rede mundial de pesos, balanças e instrumentos de medição, da qual milhões de atividades e transições diárias dependem hoje em dia.

No trabalho de Crosby (1999) também há discussão das inovações, tais como relógios mecânicos, e o desenvolvimento da cartografia moderna, expondo, em linhas gerais, como uma abordagem mais quantitativa da realidade dava aos europeus grandes meios para medir o tempo, como também o espaço, subsídios com os quais auxiliava na exploração e conquistas de novas terras. Nos trabalhos de Hogben (1958), Boyer (1974), Eves (1995) e Lima e Moises (1998) há também grande discussão dos aspectos matemáticos correlacionados as grandezas e medidas.

De certo, atravessando os séculos, percebe-se historicamente que os povos criaram medidas das mais diversas formas, mostrando que os seres humanos vêm improvisando meios de medição desde o nascimento da civilização. Hoje possuímos um Sistema Internacional de Unidades (SI), adotado por quase todos os países do mundo.

Com base em análises teóricas, percebe-se que a ideia de transmissão dos aspectos da construção histórica dos conceitos matemáticos na relação de ensino e aprendizado, ao longo dos séculos, e dos processos de educação, ocorreu através das necessidades humanas estabelecidas ao logo da história, e de fato, alguns conteúdos só continuam fazendo parte da grade curricular porque fazem parte da necessidade de 
aprendizado para uma construção gradual da sociedade. Ou seja, a matemática contribui para a solução de problemas relevantes para o convívio social (Moura, 2001), o que abre espaço para as pesquisas históricas, culturais e filosóficas acerca da matemática.

A matemática pode ser entendida como uma manifestação cultual diversificada que vem por meio de um processo histórico da integração de costumes, valores e crenças. Assim, é notório destacar que a matemática desenvolvida nos ambientes escolares é, de fato, apenas uma das mais distintas formas e maneiras que ela aparece e é desenvolvida pela humanidade, e de maneira plausível, é possível enfatizar que a matemática atua de maneira objetiva e certeira no desenvolvimento científico, tecnológico e econômico. Relacionando aos aspectos das grandezas e suas unidades de medida, Pires (2000) disserta que este apresenta grande relevância social, uma vez que diariamente estamos envolvidos com situações onde devemos mensurar o tempo, temperatura, comprimento, massa e capacidade, deste modo, este tema proporciona uma rica e grande abordagem de situações com as quais podemos e conseguimos articular diversos campos da matemática.

\section{Origem das Grandezas e suas unidades de medida}

Analisando toda a história e evolução da humanidade, nota-se que a primeira maneira que os homens antigos utilizaram para medir, e de certo, quantificar os objetos, eram simples, usavam partes do próprio corpo como instrumento. Nos tempos antigos, os povos comparavam a massa de dois objetos equilibrando-os um em cada mão, e para determinar o peso, era utilizada a sensação que cada objeto causava em seus dois braços, ou seja, esta era uma comparação corpórea, uma vez que se baseava na sensação de cada indivíduo.

A partir do momento que o homem passou a viver em aglomerados maiores, e de tal forma, estes cresciam cada vez mais, as necessidades de medir com maior eficiência também aumentava. Quando começaram a trocar os bens necessários à sua sobrevivência, foi preciso uma maneira de medir massa que não ficasse restrita a sensações corpóreas de cada um dos indivíduos, uma vez que era muito imprecisa (RHEINBOLDT, 1988).

No início dos tempos, o homem comparava a massa de dois corpos por meio do equilíbrio em cada mão. Por volta do ano cinco mil antes de Cristo, os egípcios cientes 
que o ouro era um dos metais mais precisos e não poderia compará-lo e trocá-lo usando os braços como comparação, eles inventaram a balança para o pesarem. Deste modo, com a grande necessidade de comparar, tal como pesar os metais preciosos, a balança materializou-se (RHEINBOLDT,1988). Assim, a balança, objeto hoje insubstituível em todas as atividades humanas, exerceu, de maneira substancial, uma grande importância no que diz respeito ao crescimento e evolução da humanidade. Muitas obras artísticas, seja atual ou muito antiga, apresentam expressões e representações de desenhos de balanças, destacando sua importância e visibilidade (figura 1).

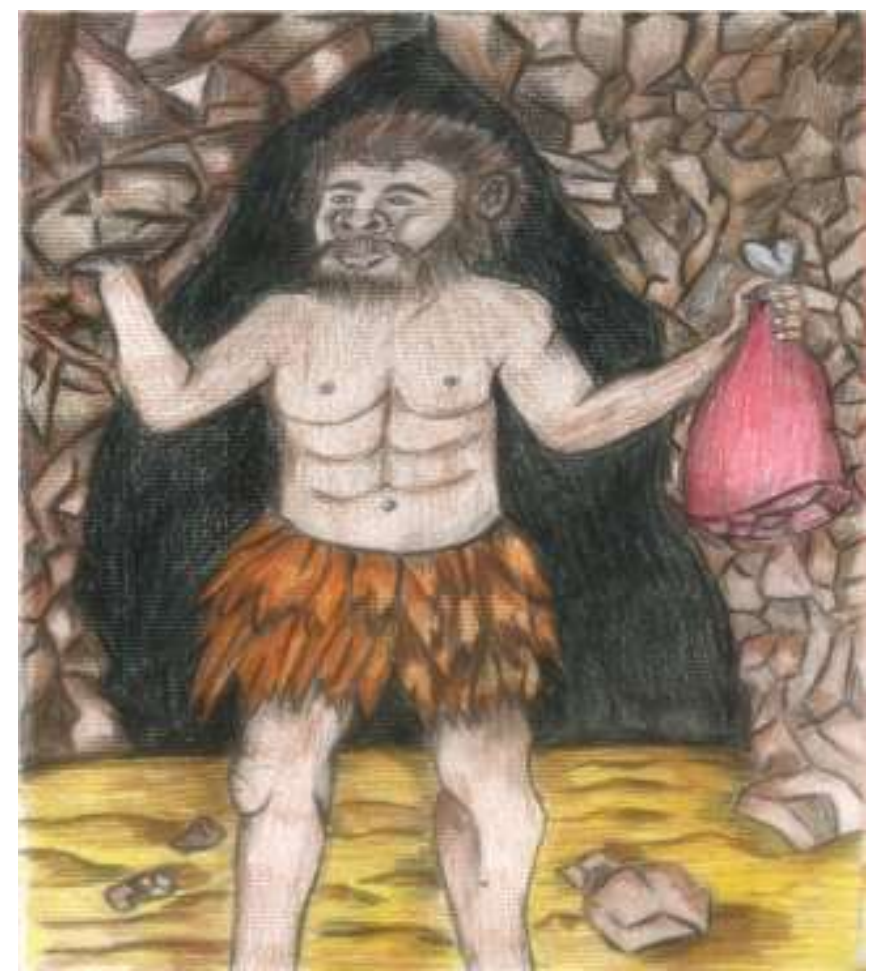

Figura 1 - O homem e a comparação de massas com o simples uso das mãos

Fonte: Elaborado por Débora Francisca de Oliveira.

Todavia, ao longo das análises históricas, percebe-se que os homens usavam partes do próprio corpo, não somente para pesagem, mas como também para todas as atividades no que diz respeito aos princípios da contagem. O comprimento do pé, a largura da mão ou a grossura do dedo, o palmo e a passada, eram parâmetros corpóreos para medição. Todavia, de fato, essas medidas eram muito arbitrarias, ou seja, variava de sujeito e, também, de país para país, o que prejudicava e criava obstáculos no que diz respeito ao desenvolvimento das trocas comerciais. Para tentar minimizar essa subjetividade, foi adotado um novo aspecto, o tamanho de certas partes do corpo do 
monarca do país como referência, ou seja, o tamanho anatômico da sua mão (por meio do palmo), do seu polegar (polegada), o antebraço ou o braço, como também o seu pé. Os povos antigos, tais como, os egípcios, os assírios, os babilônios, os chineses, os persas e os gregos, possuíam padrões de medidas muito distintos entre si.

A unidade de medida do comprimento dos babilônios era o dedo, mas também era utilizado com grande frequência o tamanho dos pés. De maneira geral, estes povos adotaram estas formas de medida porque consideravam que a natureza natural do homem era algo que poderia ser utilizada para todas as questões da sociedade. Assim como a balança, segundo dados bibliográficos obtidos por meio do Museu Escolar da Vouzela (2018), o mais antigo padrão de medida linear, que deu origem as medidas de área e volume foram concebidas no Egito antigo, baseadas também, nas relações com o corpo humano. A unidade de comprimento originada foi denominada de côvado, e sua extensão compreendia da distância do cotovelo de um ser humano até a extremidade do dedo médio, e essa padronização se deve ao faraó Anemenés I (MUSEU ESCOLAR DA VOUZELA, 2018).

Depois de analisar documentos disponibilizados pelo Museu Escolar da Vozuela (2018), percebemos que de fato, a importância das grandezas e suas unidades de medida foram atestadas no Egito antigo. Tem-se que com a inundação anual do rio Nilo, os agricultores sentiram a necessidade do desenvolvimento de métodos e instrumentos específicos que fossem capazes de medir suas terras, com base nas cheias desse rio, e esta se deu com base em marcas nas margens dos rios feitas com pedras. Essa medida agrária também originou uma atividade denominada "esticador de corda", e isso se constituía dos agrimensores medirem as plantações com cordas graduadas conosco, onde cada nó correspondia a dois côvados. Observa-se que este método perdura até hoje, com o que denominamos de agrimensor. A partir das medidas registradas era calculado a quantidade aproximada de grãos que o camponês poderia obter, para que assim, fraudes fossem evitadas.

Outro instrumento de medição criado pelos egípcios foi o fio de prumo que era usado para nivelar as superfícies para determinar a distância vertical. Este foi usado como ferramenta de alinhamento das direções norte, sul, leste e oeste na construção das famosas pirâmides de Gizé (Museu Escolar da Vouzela, 2018). Demonstrando que os egípcios também utilizaram os astros como guias. Este foi muito usado por carpinteiros, 
pedreiros e outros artesãos para conseguir dados precisos das distâncias horizontais na construção de paredes de estruturas.

Assim, percebemos que as medidas corpóreas já estavam deixando de ser algo usado pelos povos para a adoção de medias mais precisas, e eles precisavam de algo padrão para unificar as trocas comerciais e fazer jus a mercadoria e seu real valor, uma vez que a subjetividade atrapalhava as ações do comércio. Deste modo, os povos antigos começaram a desenvolver diferentes pesos e medidas para atender às necessidades da sua população. Segundo informações de do Museu Escolar de Vouzela (2018) que o grão de trigo foi possivelmente o primeiro elemento padrão de peso.

A civilização babilônica também gerou muitos padrões referentes às medidas, e a mais antiga unidade era a chamada de mina, que era um padrão de peso que variava de 500 a 600 gramas. Outro dos primeiros padrões de medida de comparação e que conhecemos até hoje é o sal. De fato, o dinheiro que recebemos após um período de trabalho o chamamos de salário, e isso perdura desde o Império Romano. A origem do termo salário veio de um aspecto histórico peculiar. $\mathrm{Na}$ época que prevaleceu o Império Romano, os soldados eram pagos com sal, e o sal era uma iguaria muito cara, que podia ser trocada por alimento, armas e, também, vestimentas (MUSEU ESCOLAR DA VOUZELA, 2018).

No período romano, havia certas unidades de peso já estabelecidas, sendo elas o talento que servia para medir grandes quantidades de metais preciosos, e a libra para medir pequenas quantidades. Essas unidades tiveram como origem termos oriundos da antiga Mesopotâmia, sendo criadas na Suméria. Ou seja, ao logo do período histórico antes de Cristo, os povos antigos já tinham conhecimento acerca da preciosidade de alguns metais e de certos elementos. O comércio, de fato, foi um dos fatores que levou a sociedade a pensar, refletir e criar unidades de medida padrão que saísse dos aspectos corpóreos, uma vez que este traçava linhas subjetivas oriundas de vários observadores e referenciais (MUSEU ESCOLAR DA VOUZELA, 2018).

$\mathrm{Na}$ Inglaterra, Ricardo I, que governou de 1189 até 1199, determinou unidades para comprimento e, também, para capacidade. O que revolucionou saberes científicos a época. Estas unidades eram de ferro, e eram mantidas em várias regiões do país cuidadas por autoridades locais a fim de comprovar a veracidade das medidas. Desta época, a jarda e o galão foram criados, e ainda são usados por alguns países de língua 
inglesa. A origem da unidade "jarda", como medida de comprimento, vem do século XII quando o rei Henrique I, adotou a distância entre seu nariz e o polegar de seu braço estendido como uma jarda. De fato, o termo jarda ainda é usado como medida em alguns lugares ao redor do mundo (MUSEU ESCOLAR DA VOUZELA, 2018).

As comunidades tinham unidades locais de medida, mas com a crescente demanda por padrões comuns internacionais de medida, em 1790, os franceses criaram o sistema métrico. Neste período a França estava passando pelo período histórico que denominamos de Revolução Francesa, e esta estava em busca do recomeço da sua vida social, e sobretudo, econômica. Foi criada uma comissão com distintos cientistas para estudar as questões e problemáticas das medidas, e esta comissão teve como membro Borda, Condorcert, Lagrange, Laplace, Delambre, Bertholet, Prony, Mechain e Monge. Esta comissão elaborou um relatório que no ano de 1795 virou um decreto Frances onde estabelecia como unidade padrão de comprimento, e de certo, base do novo sistema métrico, o metro.

Após a revolução francesa, e também a revolução industrial, e as duas guerras mundiais que revolucionaram o mundo atual, um padrão de unidades específicas e de ordem global precisou ser criada, uma vez que a globalização estava cada vez mais presente nas perspectivas de cada nação, ou seja, novamente a questão das negociações comerciais entrou em jogo buscando uma perspectiva mais unificada para os povos. Assim, em 1960, na décima primeira conferência geral de pesos e medidas foi criado o sistema internacional de unidades, denominado SI, e tinha como finalidade uma busca pela padronização das unidades de medida para as inúmeras grandezas existentes entre as nações a fim de facilitar a sua utilização, assim como, unificar, tal como, facilitar a comunicação comercial, e assim, tornar as relações mais acessíveis a todos.

Deste modo, nos dias de hoje possuímos um Sistema Internacional de Unidades aceito pela maioria dos países do mundo, o que facilita as comparações e entendimento de fenômenos físicos e naturais que acontecem nas regiões, facilita as trocas comerciais entre os países e, também, os estudos estatísticos das condições globais. Assim, há conferências mundiais que discutem acerca das unidades de medida global, e indicam mudanças ou revisão de dados. No ano de 2018, última conferência geral de pesos e medidas, tivemos que o quilograma foi redefinido em termos da constante de Planck. 


\section{Conclusão}

Com base nos Parâmetros Curriculares Nacionais Brasileiro (BRASIL, 1998), seja do ensino médio das áreas de física, química e matemática, como também do ensino fundamental da área de matemática, e na Base Nacional Comum Curricular (BRASIL, 2018) percebemos a importância do exercício de práticas de ensino e aprendizado sobre as grandezas e suas unidades de medida, uma vez que esta está presente em toda a realidade e realização humana.

De fato, percebemos que hoje, devido ao perfil subjetivo do aluno dentro de sala de sala estar mudando, o conteúdo de matemática, devido a grande abstração, precisa se adaptar as características dos alunos, referente à forma e estética, ou seja, o professor deve fazer com que o conteúdo a ser ensinado seja atrativo e significativo para o aluno para que ele se aproprie deste saber. É interessante e muito importante que o professor destaque para os alunos as diferentes formas pelas quais os homens historicamente começaram a fazer medidas e quantificar as coisas. Ou seja, a compreensão das relações entre as unidades que possuímos hoje fica mais clara quando se retoma termos e aspectos históricos.

A matemática sofre, não só hoje, mas por um longo período histórico, aversão por parte dos alunos, e isso se deve ao fato de sua grande abstração. Baseado nas perspectivas de Paulo Freire, principalmente na obra Educação e Mudança, percebe-se que o professor deve, de maneira significativa, criar um laço entre o conteúdo a ser ensinado e a realidade do aluno. Este pressuposto muito se encaixa as questões de história e filosofia das ciências, ou seja, quando há transmissão de conhecimentos históricos e de significados, haverá mais alunos interessados no conteúdo.

A história da matemática favorece uma construção do saber gradual no aluno, e traz o brilhantismo das realizações das atividades humanas. De maneira geral, os aspectos desta natureza traduzem uma versão mais coesa e coerente da matemática, e não fica restrita a visão pequena de abstração, e expõe que esta é uma ciência que apesar de exata, necessita de condições temporais e, também, sociais.

As grandezas e suas unidades de medida são de suma importância para a evolução e construção da sociedade, e nota-se isso com base em sua história, uma vez que esta foi a base do crescimento das relações humanas. Todas as grandezas possuem suas unidades de medida que precisa ser aprendido pelos alunos para que eles 
participem dessa interação com a sociedade como agente ativo, e cidadão praticante. A melhor forma de mostrar aos alunos que as grandezas são importantes e que eles precisam aprender é fazendo contextualizações, e a história da matemática apresenta aspectos que viabilizam este processo.

Assim, se o professor no início de um conteúdo matemático fizer uma contextualização e abordagem histórica, maior será a quantidade de alunos interessados no conteúdo, uma vez que ele verá a importância de aprender tal conteúdo e onde ele pode se encaixar em sua realidade, participando assim, da apropriação do conhecimento.

Percebemos também com a realização deste trabalho de que, de maneira geral, a construção histórica dos conceitos matemáticos começou a ter origem a partir das necessidades humanas, visto aos pressupostos da necessidade momentânea. De fato, alguns conceitos das grandezas e suas unidades de medida estão presentes nas escolas brasileiras, uma vez que apresentam grande relação com atividades do cotidiano. Reafirmando a fala de Moura (2001, p.148), as atividades das grandezas estão na grade curricular uma vez que contribuem para a solução de problemas ainda relevantes para o convívio social.

Nos Parâmetros Curriculares Nacionais das áreas de Física, Química e Matemática (BRASIL, 1998) há indicação sobre a importância da abordagem dos aspectos históricos no processo de ensino, e de maneira geral, quando referenciado aos aspectos das grandezas e suas unidades de medida, é enfatizado que estes abrem grande espaço e oportunidade para o trabalho com aspectos históricos da construção deste conhecimento, uma vez que deste a antiguidade as civilizações tiveram atividade matemática relacionada à prática de comparação de grandezas.

Deste modo, mesmo que a matemática tenha um caráter mais abstrato e apresente mais cálculos de fenômenos, o professor pode levar para a sala de aula aspectos da história da matemática para contribuir com sua didática. Uma vez vista que a história da matemática é rica nas questões filosóficas da sociedade, e que também mostra a importância que a matemática teve para a evolução dos padrões de medida, pode ser abordado em sala perspectivas oriundo de que o conhecimento e criação de sistemas padrão de unidades vêm conforme a necessidade da sociedade por questões mais específicas. Logo, deste modo, tem-se que abordar aspectos da história das 
Grandezas e medidas: da origem histórica à contextualização curricular

João Pedro Mardegan Ribeiro

grandezas e suas unidades de medida favorece uma melhor visão do aluno pelo conteúdo matemático propriamente dito.

\section{Referências}

BOYER, C. B. História da matemática. Tradução: Elza F. Gomide. São Paulo, Edgard Blucher, 1974.

BRASIL. Base Nacional Comum Curricular: Ensino Fundamental. Brasília: MEC/Secretaria de Educação Básica, 2018.

BRASIL. Ministério da Educação. Parâmetros Curriculares Nacionais: terceiro e quarto ciclos: Matemática. Brasília: MECSEF, 1998.

BRASIL. Ministério da Educação. CNE/CEB. Diretrizes Curriculares Nacionais da educação básica. Brasília, 2013.

BRASIL. Ministério da Educação. Parâmetros curriculares nacionais do ensino médio: Ciências da Natureza, Matemática e suas tecnologias. Brasília: MEC/SEMTEC, 1998.

CREASE, R. P. A. Medida do Mundo - A Busca Por Um Sistema Universal de Pesos e Medidas. Trad. George Schlesinger; revisão técnica Diego Vaz Bevilaqua. 1ed. Rio de Janeiro, Zahar, 2013.

CROSBY, A. W. A mensuração da realidade: a quantificação e a sociedade ocidental, 1250 - 1600. Tradução Vera Ribeiro. São Paulo: Editora Unesp, 1999.

EVES, H. W. Introdução à história da matemática. Unicamp, 1995.

FIORENTINI, D.; LORENZATO, S. Investigação em educação matemática: percursos teóricos e metodológicos. Campinas, SP: Autores Associados, 2006.

FREIRE, P. Educação e mudança. 15 ed. Rio de Janeiro: Paz e terra, 1979.

HOGBEN, L. Maravilhas da Matemática. trad. Paulo M. da Silva, Roberto Bins e Henrique C. Pfeifer, Rio de Janeiro, Editora Globo, 1958.

KULA, W. Las medidas y los hombres. Siglo XXI, 1999.

LIMA, L.; MOISÉS, R. P. A fração: a repartição da terra. São Paulo: CETEAC/CIART, 1998.

MOURA. M. O de. A Atividade de Ensino como ação formadora. In. CASTRO, A. D. de; CARVALHO, A. M. P. de (orgs.). Ensinar a ensinar: didática para a escola fundamental e média. São Paulo: Pioneira Thompson Learning. P. 143-162. 2001. 
MUSEU ESCOLAR DE VOUZELA. Coleção Museológica. O Patrimônio Escolar. Apontamentos sobre as Antigas Medidas de Peso, Volume e Comprimento. Vouzela, s/d. Disponível em: http://slideplayer.com.br/slide/1813337/. Acesso em 8 de Maio de 2018.

PIRES, C. M. C. O Que Ensinar em Matemática. São Paulo: PUC, 2000.

RHEINBOLDT, H. História da balança e a vida de J.J Berzelius. São Carlos: Livro, 1988. 293 p. Acesso em: Biblioteca da Escola de Engenharia de São Carlos da Universidade de São Paulo.

SÃO PAUlO. Secretaria da Educação. Currículo do Estado de São Paulo: Matemática e suas tecnologias / Secretaria da Educação; coordenação geral, Maria Inês Fini; coordenação de área, Nilson José Machado. - 1. ed. atual. - São Paulo: SE, $2012.72 \mathrm{p}$.

SILVA, I.. História Dos Pesos e Medidas. São Carlos: EdUFSCar, 2010. 